\title{
Author Correction: Global geochemical fingerprinting of plume intensity suggests coupling with the supercontinent cycle
}

\author{
Hamed Gamal EL Dien (1D, Luc S. Doucet, Zheng-Xiang Li(D), Grant Cox \& Ross Mitchell
}

Correction to: Nature Communications https:/doi.org/10.1038/s41467-019-13300-4, published online 21 November 2019.

The original version of this Article omitted from the author list the 4th and 5th authors, Grant Cox and Ross Mitchell, who were both at Curtin University. Consequently, the corrected version of the Acknowledgements removes the following from the original version: 'and Ross Mitchell'. In addition, the following was added to the Author Contributions: 'G.M.C. and R.M. were involved in an early attempt of this study.'. This has been corrected in both the PDF and HTML versions of the Article.

Published online: 05 June 2020

Open Access This article is licensed under a Creative Commons Attribution 4.0 International License, which permits use, sharing, adaptation, distribution and reproduction in any medium or format, as long as you give appropriate credit to the original author(s) and the source, provide a link to the Creative Commons license, line to the material. If material is not included in the article's Creative Commons license and your intended use is not permitted by statutory regulation or exceeds the permitted use, you will need to obtain permission directly from the copyright holder. To view a copy of this license, visit http://creativecommons.org/licenses/by/4.0/.

(c) Crown 2020 